\title{
Sintesis Carbon Nanotube (CNT) Menggunakan Prekursor Bahan Alam Serta Modifikasi CNT Sebagai Komposit CNT/Resin Epoksi: Review
}

\section{Synthesis of Carbon Nanotubes (CNT) Using Natural Material Precursors and Modified CNTs as CNT/Epoxy Resin Composite: Review}

\author{
Putri Ayu Anggoro dan Teguh Endah Saraswati* \\ Program Studi Kimia, Fakultas Matematika dan Pengetahuan Alam, Universitas Sebelas Maret \\ Jl. Ir. Sutami 36A Kentingan, Surakarta, Indonesia, 57126 \\ *Email: teguh@mipa.uns.ac.id
}

\begin{abstract}
Abstrak. Carbon Nanotube (CNT) memiliki aplikasi potensial yang luas karena sifat kimia dan fisiknya yang sangat baik. CNT disintesis menggunakan prekursor cair dari bahan alam yang. Prekursor cair dari bahan alam dimungkinkan dapat mengganti prekursor berbasis minyak bumi. Minyak kamper, jarak, kayu putih, dan kelapa sawit digunakan sebagai reservoir karbon untuk menghasilkan CNT berdinding banyak (MWCNT). Berbagai metode telah digunakan untuk menghasilkan CNT, termasuk ablasi laser, arc discharge dan proses deposisi uap kimia (CVD). Ulasan ini menjelaskan pembuatan CNT menggunakan metode CVD dikarenakan metode ini adalah metode yang umum digunakan dan sederhana. MWCNT yang dihasilkan dimodifikasi untuk membentuk komposit dengan resin epoksi.
\end{abstract}

Kata kunci: Carbon nanotube, modifikasi CNT, komposit, resin epoksi

\begin{abstract}
Carbon Nanotubes (CNT) have wide potential applications due to their excellent chemical and physical properties. CNTs were synthesized using liquid precursors from natural materials possibly replacing petroleum-based precursors. Camphor, jatropha, eucalyptus oil, and palm oil are used as carbon reservoirs to produce multi-walled carbon nanotubes (MWCNT). A variety of methods have been used to produce CNTs, including laser ablation, arc discharge, and chemical vapor deposition (CVD) processes. This mini-review explained the manufacture of CNTs using the CVD method as a commonly used and simple method. The synthesized CNT is then modified to be applied to form a composite with epoxy resin.
\end{abstract}

Keywords: Carbon Nanotube, CNT modification, composite, epoxy resin

\section{Pendahuluan}

Carbon Nanotube (CNT) adalah serat karbon ultra tipis yang diameternya berukuran nanometer dan panjang berukuran mikrometer. CNT pertama kali ditemukan oleh seorang ilmuwan Jepang, Sumio Iijima, pada katoda karbon yang digunakan untuk proses pelepasan busur mempersiapkan gugus karbon kecil yang diberi nama fullerene [1]. CNT memiliki sifat yang unik dan berbagai aplikasi sehingga menjadi salah satu bahan yang paling aktif dieksplorasi dalam beberapa tahun terakhir. Produksi CNT dalam skala besar secara ekonomis sangat penting untuk mewujudkan aplikasi ini [2]. CNT menarik banyak penelitian dan menjadi salah satu nanomaterial paling terkenal karena memiliki sifat yang sangat baik serta aplikasi potensial. 
Pengembangan lebih lanjut dari studi ini membutuhkan pengendalian fitur yang lebih tepat untuk pertumbuhan CNT, seperti panjang, diameter dan posisi kiralnya [3]. Struktur CNT terdiri dari lembar grafit yang tergulung dan dapat diklasifikasikan menjadi CNT berdinding ganda atau berdinding tunggal (MWCNT atau SWCNT) tergantung pada metode persiapannya [4].

CNT dapat dibuat dalam dua bentuk dasar yaitu SWCNT (gambar 1) dan MWCNT. Secara struktural, SWCNT dapat dibandingkan dengan lembaran grafit setebal satu atom yang digulung yang disebut graphene. SWCNT terdiri dari satu tabung graphene sedangkan MWCNT terdiri dari beberapa tabung konsentris graphene dipasang satu di dalam yang lain. SWCNT memiliki diameter berukuran beberapa nanometer, sedangkan pada MWCNT memiliki diameter berukuran puluhan nanometer [5].

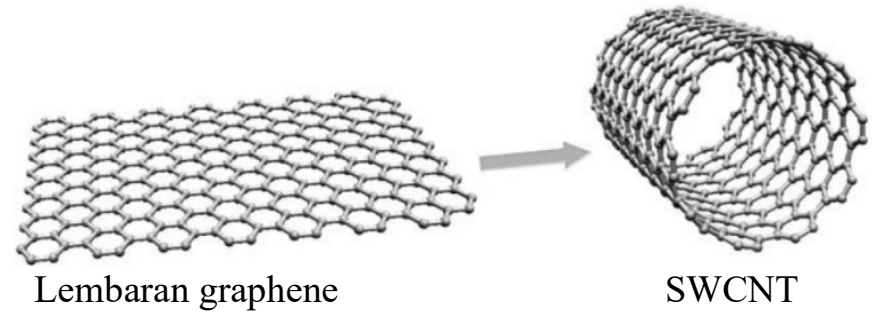

Gambar 1. Pembentukan SWCNT dari lembaran graphene [5]

Sintesis CNT dapat menggunakan metode pelepasan busur, ablasi laser dan deposisi uap kimia (CVD). CVD telah dilaporkan menjadi metode produksi skala besar CNT yang sangat disukai untuk memenuhi permintaan yang meningkat untuk beberapa perkembangan teknologi [6]. CVD adalah metode yang paling menjanjikan untuk produksi CNT skala besar. CVD membutuhkan suhu reaksi yang lebih rendah dan biaya yang lebih rendah [7]. Saat ini, masalah kritis untuk aplikasi komersial CNT adalah produksi berskala besar. Harga CNT yang tinggi namun baru-baru ini turun, tetapi masih berlebihan untuk industrialisasi yang realistis [8].

Produksi bahan nano dapat ditekan biayanya dari sumber daya terbarukan. Bahan baku hayati yang tersedia di alam dalam jumlah tinggi seperti biopolimer atau senyawa kimia turunan hayati seperti minyak esensial memiliki berbagai keunggulan dibandingkan dengan prekursos sintetis. Mereka memiliki kandungan karbon yang tinggi sehingga cocok sebagai bahan penyusun untuk sintesis nanokarbon. Selain itu, harganya yang murah dan keberadaannya yang melimpah karena terus diisi ulang oleh alam. Kamper, hidrokarbon tumbuhan $\left(\mathrm{C}_{10} \mathrm{H}_{16} \mathrm{O}\right)$ dapat digunakan untuk mensintesis $\mathrm{CNT}$ dengan hasil yang menjanjikan [9]. Selain itu minyak kayu putih $\left(\mathrm{C}_{10} \mathrm{H} 18 \mathrm{O}\right)$ telah ditemukan sebagai prekursor lain yang menjanjikan untuk sintesis CNT. Minyak kayu putih sangat murah dan mudah diperoleh dari sumber daya terbarukan [10]. Prekursor dari bahan baku hayati dapat menggantikan prekursor yang terkait bahan fosil seperti karbon monoksida, metana, asetilena, benzena, xilena yang semakin hari semakin krisis [11].

CNT berbasis komposit polimer memiliki banyak aplikasi potensial karena sifat mereka yang luar biasa. Namun, kecenderungan kuat MWCNT untuk membentuk aglomerat (karena gaya Van der Waals) membuat nanotube tidak kompatibel dengan matriks polimer [12]. Beberapa perlakuan khusus CNT, seperti perlakuan fisik atau kimia digunakan untuk mencapai dispersi CNT yang lebih baik dan antarmuka yang lebih baik antara matriks polimer dan CNT sehingga CNT dapat dimanfaatkan secara optimal sebagai komponen penguat matriks polimer [13]. Metode kimiawi menggunakan surfaktan atau fungsionalisasi kimiawi permukaan tabung yang meningkatkan ikatan antar muka dan dapat mencegah agregasi tabung. Sedangkan metode fisik melibatkan ultrasonikasi, penggilingan untuk secara fisik memisahkan tabung yang digabungkan Bersama [14]. Ulasan ini akan membahas prekursor dari bahan alam untuk sintesis CNT serta modifikasi CNT sehingga dapat dimanfaatkan secara optimal sebagai penguat matriks polimer. 


\section{Pembahasan}

\subsection{Sintesis Carbon Nanotube (CNT)}

Deposisi Uap Kimia (CVD) menjadi metode sintesis CNT yang paling populer dan merupakan salah satu metode yang dapat mengadaptasi berbagai jenis bio-feedstock secara luas [15]. CVD memiliki prinsip dekomposisi katalitik hidrokarbon di atas logam transisi katalis yang didukung. CNT yang diproduksi oleh metode CVD memiliki ciri-ciri yang bergantung pada kondisi eksperimental seperti suhu, tekanan, volume, konsentrasi dan sifat hidrokarbon, waktu reaksi, perlakuan awal katalis dan katalis [16]. Sintesis CNT oleh CVD terdiri dari dua proses yaitu langkah persiapan katalis kemudian langkah sintesis dari CNT . CNT akan terbentuk jika parameter yang tepat dipertahankan dalam proses [17]. Proses sintesis CNT dengan metode CVD diasumsikan non-isotermal dan proses non-adiabatik. Dalam analisis yang disajikan, rangkaian rangkaian aliran plug dan reaktor batch diasumsikan memodelkan fase reaksi. Hal ini menunjukkan bahwa proses pembentukan CNT memiliki spasi dan ketergantungan waktu [18]. Skema rangkaian CVD termal ditunjukkan pada Gambar 2.

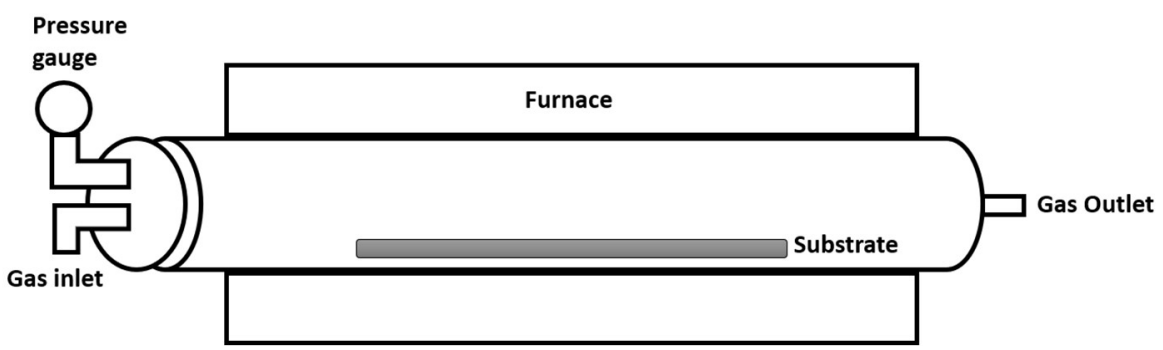

Gambar 2. Skema rangkaian CVD termal

Selama pengendapan uap kimiawi, bahan baku karbon dalam bentuk hidrokarbon diuraikan pada suhu tertentu menjadi gas karbon yang diendapkan pada katalis logam transisi seperti besi, kobalt, atau nikel. Dalam hal sumber gas karbon, efisiensi pertumbuhan CNT sangat bergantung pada reaktivitas dan konsentrasi antara fase gas yang diproduksi bersama dengan spesies reaktif dan radikal bebas sebagai akibat dari penguraian hidrokarbon [5]. Sintesis CNT dengan dekomposisi hidrokarbon suhu tinggi, menunjukkan bahwa sifat termodinamika dan struktur kimia prekursor hidrokarbon berperan penting dalam morfologi endapan karbon di atas katalis [19].

Pada prosedur CVD, sumber karbon dimasukkan ke tungku bersuhu tinggi yang disimpan pada $700^{\circ} \mathrm{C}$ atau lebih di mana substrat dilapisi dengan partikel katalis, misalnya, besi atau nikel. Sebagai alternatif, ferosen atau nikel dapat diinjeksikan bersama dengan bahan baku untuk membentuk partikel katalis in situ [20]. Selama proses, bantalan molekul karbon (dari bio-feedstock / petroleum) deposit pada kelompok katalis yang terbuat dari nanopartikel logam (tersuspensi atau tidak bergerak, masing-masing), di mana mereka memecah menjadi unsur karbon. Setelah aliran yang stabil dari blok penyusun ini terbentuk, CNT dirakit secara kontinyu, tetapi perlambatan disebabkan oleh penonaktifan bertahap oleh katalis [21]. Tipikal substrat pada CVD yang dipanaskan terkena satu atau lebih prekursor yang mudah menguap, yang terurai di dekat atau di permukaan substrat untuk membentuk deposit padat. Akibat reaksi yang terjadi, produk samping yang mudah menguap juga dihasilkan. Reaksi kimia spesies prekursor terjadi baik di fase gas dan juga di fase padat; permukaan pengendapan. Reaksi CVD secara umum adalah termodinamika endotermik oleh karena itu energi harus disuplai ke reaktor. Secara tradisional, reaksi pada CVD dipromosikan atau diprakarsai oleh panas (CVD termal) [22]. Katalis kobalt, besi dan nikel yang didukung pada silika, alumina dan magnesium oksida, sering digunakan dalam CVD. Selain itu, logam lain telah terbukti cocok untuk pertumbuhan $\mathrm{CNT}$ seperti $\mathrm{Pd}, \mathrm{Pt}, \mathrm{Ru}, \mathrm{Au}, \mathrm{Mn}, \mathrm{Cu}, \mathrm{Ag}$ dan lantanida seperti Gd dan Uni Eropa. Campuran lainnya senyawa seperti $\mathrm{FeSiO} 2, \mathrm{SiC}$ dan $\mathrm{ZnO}$ juga telah digunakan. Ketika promotor ditambahkan ke katalis logam, seperti molibdenum atau vanadium, aktivitas katalis bimetalik lebih tinggi 
dari katalis monometalik, sebagai penambahan sebuah promotor menghasilkan efek menstabilkan, mencegah aglomerasi fase aktif katalis dan meningkatkan hasil dan grafitisasi CNT [23].

Sebagian besar teknik sintesis CNT memerlukan introduksi katalis berupa partikulat gas atau sebagai pendukung padat. Pemilihan katalis logam dapat mempengaruhi pertumbuhan dan morfologi nanotube. Aktivitas katalitik Fe, Co, atau Ni sebagai katalis, dan pelat vanadium dengan perlakuan laser yang memiliki luas permukaan tinggi sebagai pendukung katalis dalam dekomposisi asetilena pada $720^{\circ} \mathrm{C}$ pada perlakuan CVD dibandingkan oleh Seo dkk. [24] . CNT dengan kualitas terbaik diperoleh dari katalis besi dengan kepadatan tinggi dengan ukuran diameter yang kecil yaitu 10-15 nm. Sedangkan Nagaraju dkk [7] membandingkan aktivitas katalitik Fe, Co dan Fe / Co yang didukung pada alumina atau silika. Hasil MWCNT terbaik dihasilkan pada suhu $700^{\circ} \mathrm{C}$ pada alumina terhidrasi yang dibuat dari aluminium isopropoksida dan mengandung campuran Fe dan Co di dalamnya.

Pada proses sintesis CNT proses pemurnian menjadi hal yang perlu dipertimbangkan. Hal ini disebabkan oleh pengotor yang biasanya yang terdapat pada produk sebagai hasil samping dari katalis yang digunakan, atau berbagai parameter seperti suhu yang digunakan dalam proses dekomposisi.Langkah pemurnian yang digunakan tergantung pada tingkat pengotor pada bahan. Namun, langkah-langkah ini dapat merusak struktur CNT, oleh karena itu upaya diintensifkan untuk mengurangi langkah-langkah ini dan meminimalkan atau sepenuhnya menghilangkan kandungan pengotor selama sintesis bahan-bahan ini [6].

\subsection{Prekursor untuk Sintesis $C N T$}

Prekursor dalam sintesis CNT dapat diklasifikasikan menjadi dua yaitu cair dan padat. Pada ulasan ini akan dibahas prekursor dari bahan alam berkelanjutan yang berbentuk padat cair. Kumar dan Ando [9] melakukan penelitian sintesis CNT menggunakan prekursor kamper. Metode CVD digunakan dalam sintesis ini. Jumlah kamper yang sesuai dan ferosen dimasukkan ke dalam tungku. Pada sintesis ini digunakan gas argon. Hasil CNT dari prekursor kamper menunjukkan sifat mekanik sederhana dan hidrofobisitas tinggi. Selain itu juga dihasilkan CNT berdiameter 25-50 nm kemurnian tinggi dari dekomposisi katalitik kamper Kristalinitas nanotube ini cukup baik dengan pembentukan karbon amorf sangat rendah, dan keberadaan partikel katalis dalam CNT yang tumbuh hampir dapat diabaikan. Oleh karena itu, tidak diperlukan pemurnian setelah deposisi. Minyak kamper tidak beracun sehingga dapat direproduksi prekursor. Dekomposisi prekursor hidrokarbon sangat tergantung pada kondisi lingkungan [25].

Selanjutnya Aswathi dkk. [11] melakukan penelitian mengenai sintesis CNT menggunakan prekursor minyak jarak. MWCNT disiapkan dalam hasil tinggi dengan pirolisis semprot larutan minyak jarak-ferosen pada $850^{\circ} \mathrm{C}$ di bawah atmosfer Ar. Morfologi dari diverifikasi oleh SEM dan TEM. MWCNT dengan diameter antara 20 dan $60 \mathrm{~nm}$ dihasilkan dari prekursor ini. Saat amonia ditambahkan, N-MWCNT berbentuk bambu dengan struktur terutama lurus diperoleh. Keuntungan dari teknik sintesis ini adalah kesederhanaan dan penggunaan dengan biaya rendah dan mudah didapat. Selain itu Raziah dkk. membuat percobaan sintesis MWCNT yang berhasil dengan morfologi bambu dari minyak jarak pada suhu tereduksi $300-400^{\circ} \mathrm{C}$. Untuk memfasilitasi transformasi, reaksi dilakukan di bawah pengaruh gelombang mikro.

Sintesis CNT juga dapat menggunakan prekursor minyak kayu putih. Sintesis CNT menggunakan minyak kayu putih sebagai sumber karbon diperoleh hasil yang sangat baik dengan Y-zeolit sebagai substrat katalis. CNT memiliki kemurnian tinggi dan memiliki distribusi diameter dari 0,79 hingga 1,71 nm seperti yang diperiksa dengan spektroskopi Raman. Karena minyak kayu putih terdiri dari banyak senyawa kimia bisiklik menyerupai kamper, maka memiliki tingkat kontaminasi yang rendah. Teknik sintesis ini tidak memerlukan perlakuan awal apapun dari prekursor katalis untuk menghasilkan prekursor katalis aktif oleh penggunaan gas $\mathrm{H}_{2}[10]$.

Minyak kelapa sawit memiliki kelimpahan yang tinggi dan sifatnya yang dapat diisi ulang menjadikannya bahan baku yang menarik untuk berbagai proses. Suriani dkk [26] melakukan sintesis CNT pertama menggunakan prekursor minyak kelapa saiwt dan berhasil. Campuran SWCNT dan MWCNT 
dengan kemurnian rata-rata diperoleh (ID / IG =0,52). Namun Kudin dkk. tidak berhasil mengoptimalkan kondisi untuk mendapatkan material yang bebas dari cacat atau spesies yang tidak diinginkan. Robaiah dkk. juga menghasilkan CNT dengan kristalinitas rendah dari sumber prekursor ini.

\subsection{Modifikasi CNT untuk Pembuatan Komposit CNT/Resin Epoksi}

Komposit yang mengandung CNT memiliki aplikasi penting seperti sebagai bahan struktural. Oleh karena itu, dispersi CNT dalam komposit sangat penting untuk sifat akhir bahan berstruktur nano karena dispersi yang buruk biasanya menghasilkan sifat mekanik dan antarmuka yang memburuk antara CNT dan matriks. Strategi fungsionalisasi dieksplorasi dan dikembangkan untuk mengatasi masalah tersebut sehingga dapat memperluas aplikasi CNT. Fungsionalisasi CNT adalah cara yang efektif untuk mencegahnya agregasi. Fungsionalisasi kimiawi CNT juga dapat meningkatkan interaksi antar muka antara CNT dan matriks, yang menyebabkan peningkatan sifat mekanik komposit. Peningkatan ini terkait dengan ikatan kimia (kovalen atau tidak) yang terbentuk antara gugus fungsi permukaan CNT dan matriks polimer. dua tipe fungsionalisasi CNT paling umum dilakukan di media asam atau amino [12].

Ma dkk. [14] Melakukan fungsionalisasi CNT melalui sebuah proses gabungan perawatan $\mathrm{UV} / \mathrm{O}_{3}$ dan pemutusan amina menggunakan ethylenediamine. Fungsionalisasi amino CNT dilakukan dengan kopling langsung antara amina organik dan gugus karboksilat $(-\mathrm{COOH})$ pada permukaan CNT yang dihasilkan dari perawatan UV / O3 sebelumnya. Dimethylamino-pyridine digunakan sebagai agen pengawetan. Setelah fungsionalisasi didapatkan hasil aglomerat yang hampir tidak ada dalam sampel yang mengandung amino-CNT. Hal ini menunjukkan bahwa dispersi CNT meningkat secara signifikan karena fungsionalisasi, dan peningkatan dispersi CNT distabilkan dan dipertahankan setelah resin epoksi sepenuhnya diawetkan. Fungsionalisasi amino juga meningkatkan dispersi dan interaksi antar muka CNT, menghasilkan lebih banyak perbaikan sifat mekanik komposit CNT / epoksi dibandingkan yang mengandung CNT murni.

Fungsionalisasi CNT selanjutnya dapat menggunakan triethylenetetramine (TETA). Transplantasi triethylenetetramine (TETA) pada permukaan MWCNT dapat menjembatani koneksi MWCNT ke matriks epoksi. Adanya TETA yang terikat secara kimiawi mengubah permukaan MWCNT yang halus dan tidak reaktif. Pengobatan asam pada MWCNT harus dilaksanakan terlebih dahulu pada proses fungsionalisasi agar efektif menghasilkan gugus karboksil di permukaannya. Analisis Raman dan XPS menunjukkan bahwa perlakuan $\mathrm{H}_{2} \mathrm{SO}_{4} / \mathrm{HNO}_{3}$ akan memvariasikan fitur permukaan MWCNT dan secara efisien memasukkan gugus karboksil ke dalamnya. Serangkaian modifikasi kimiawi menghasilkan penurunan kandungan kristal MWCNT secara terus menerus, sedangkan struktur MWCNT tidak banyak dipecah oleh fungsionalisasi. Dengan demikian, fungsi kimiawi yang digunakan dalam pekerjaan ini tidak hanya secara efektif menghasilkan kelompok yang dibutuhkan pada permukaan MWCNT, tetapi juga memelihara struktur MWCNT yang baik [27].

Kim dkk. [28] Melakukan fungsionalisasi permukaan MWCNT dengan mengoksidasi MWCNT dalam kondisi kuat kondisi ringan, menggunakan larutan $\mathrm{HNO}_{3}$ dan campurannya dari $\mathrm{H}_{2} \mathrm{O}_{2}$ dan $\mathrm{NH}_{4} \mathrm{OH}$, masing-masing. Namun, dalam kondisi suhu tinggi yang parah dan waktu oksidasi yang lama, MWCNT dimurnikan dengan baik, tetapi struktur kristalnya sebagian rusak. Kerusakan MWCNT dapat disebabkan oleh oksidasi yang terlalu kuat seperti konsentrasi yang sangat asam dan suhu perawatan yang tinggi. Besarnya kerusakan di MWCNT memiliki pengaruh terhadap sifat listrik dari komposit MWCNT.

Jagtap dan Ratna [12] melakukan modifikasi MWCNT dengan menggunakan garam natrium dari asam 6-aminoheksanoat (SAHA). interaksi kation- $\pi$ dengan menggunakan surfaktan telah direalisasikan sebagai cara terbaik untuk mencapai dispersi yang baik dari MWCNT dan interaksi antar muka. Kation dari pengubah semacam itu berinteraksi dengan $\pi$ awan elektron MWCNT dan mengurangi gaya Van der Waals. Metode ini tidak mengganggu $\pi$ awan elektron dari MWCNT. Pemodifikasi SAHA dirancang sedemikian rupa sehingga mengandung sebuah kation $\left(\mathrm{Na}^{+}\right)$, yang berinteraksi dengan $\pi$ awan elektron MWCNT 
melalui interaksi kation- $\pi$ dan gugus $-\mathrm{NH}_{2}$ bebas dapat membentuk ikatan kimia dengan resin epoksi. Dengan cara ini, nanotube menjadi bagian integral dari ikatan silang melalui ikatan kimia antara SAHA dan resin epoksi. Ini memberikan transfer beban yang efektif dari matriks epoksi ke nanotube untuk peningkatan sifat mekanik.

\subsection{Pembuatan Komposit CNT/Resin Epoksi}

CNT yang telah dimodifikasi permukaannya akan meningkatkan interaksi antar muka antara CNT dan matriks dan sifat mekanik komposit yang baik. Jagtap dan Ratna [12] melakukan pengkompositan MWCNT dengan resin epoksi menggunakan pelarut aseton dan tetrahydrofuran. MWCNT ditambahkan ke dalam pelarut lalu dilakukan sonikasi. Setelah itu dilakukan penambahan resin epoksi. Poli (oksipropilen) diamina digunakan sebagai agen pengawetan.

MWCNT yang difungsikan didispersi secara terpisah dalam etil alkohol absolut dan disonikasi lalu ditambah dengan resin epoksi dengan kandungan MWCNT yang sesuai. ampuran itu disonikasi dan diaduk homogenisasi. Perlakuan ini meningkatkan viskositas dari dispersi, yang pada gilirannya membatasi agregasi MWCNT. Campuran divakum untuk menghilangkan pelarut lalu ditambah agen pengawetan [27].

\section{Kesimpulan}

Sintesis Carbon Nanotube (CNT) menggunakan metode CVD memiliki keunggulan yaitu sederhana dan dapat menggunakan suhu reaksi rendah serta memiliki biaya yang lebih rendah. Prekursor dari bahan alam berkelanjutan dapat menggantikan prekursor dari bahan fosil yang semakin lama semakin menipis. Selain itu prekursor bahan alam memiliki harga yang lebih terjangkau, mudah didapat, serta keberadaannya yang melimpah. Minyak kayu putih dan kamper menjadi sumber karbon dalam sintesis CNT dengan hasil kemurnian paling baik di antara sumber karbon dari bahan alam lainnya. Pemodifikasi permukaan CNT dapat dilakukan dengan fungsionalisasi menggunakan asam atau amino untuk meningkatkan interaksi antar muka antara CNT dan matriks dan sifat mekanik komposit yang baik. Selain itu juga dapat menggunakan interaksi kation- $\pi$ dengan menggunakan surfaktan. Kation dari pemodifikasi berinteraksi dengan $\pi$ awan elektron MWCNT dan mengurangi gaya Van der Waals.

\section{Referensi}

[1] Sato, H., Sano, M., 2008, Characteristics of Ultrasonic Dispersion of Carbon Nanotubes Aided By Antifoam, Colloids and Surfaces A: Physicochemical and Engineering Aspects, 322(1-3), 103-107.

[2] Raji, K., Thomas, S., Sobhan, C. B., 2011, A Chemical Kinetic Model for Chemical Vapor Deposition of Carbon Nanotubes, Applied Surface Science, 257(24), 10562-10570.

[3] Lee, Y. T., Park, J., Choi, Y. S., Ryu, H., Lee, H. J., 2002, Temperature-Dependent Growth Of Vertically Aligned Carbon Nanotubes In The Range $800-1100^{\circ}$ C, The Journal of Physical Chemistry B, 106(31), 7614-7618.

[4] Pillay, K., Cukrowska, E. M., Coville, N. J., 2009, Multi-Walled Carbon Nanotubes as Adsorbents for the Removal of Parts per Billion Levels of Hexavalent Chromium From Aqueous Solution, Journal of Hazardous Materials, 166(2-3), 1067-1075.

[5] Prasek, J., Drbohlavova, J., Chomoucka, J., Hubalek, J., Jasek, O., Adam, V., Kizek, R., 2011, Methods for Carbon Nanotubes Synthesis, Journal of Materials Chemistry, 21(40), 15872-15884.

[6] Afolabi, A. S., Abdulkareem, A. S., Iyuke, S. E., 2007, Synthesis Of Carbon Nanotubes and Nanoballs By Swirled Floating Catalyst Chemical Vapour Deposition Method, Journal of Experimental Nanoscience, 2(4), 269-277.

[7] Nagaraju, N., Fonseca, A., Konya, Z., Nagy, J. B., 2002, Alumina and Silica Supported Metal Catalysts for the Production of Carbon Nanotubes, Journal of Molecular Catalysis A: Chemical, 181(1-2), 57-62. 
[8] Łamacz, A., 2019, CNT and H2 Production during CH4 Decomposition Over Ni/Cezro2. I. A Mechanistic Study, Chemengineering, 3(1), 26.

[9] Kumar, M., Ando, Y., 2003, Single-Wall and Multi-Wall Carbon Nanotubes from Camphor-A Botanical Hydrocarbon, Diamond and Related Materials, 12(10-11), 1845-1850.

[10] Ghosh, P., Afre, R. A., Soga, T., Jimbo, T., 2007, A Simple Method of Producing Single-Walled Carbon Nanotubes From A Natural Precursor: Eucalyptus Oil, Materials Letters, 61(17), 3768-3770.

[11] Awasthi, K., Kumar, R., Raghubanshi, H., Awasthi, S., Pandey, R., Singh, D., Srivastava, O. N., 2011, Synthesis of Nano-Carbon (Nanotubes, Nanofibres, Graphene) Materials, Bulletin of Materials Science, 34(4), 607.

[12] Jagtap, S. B., Ratna, D., 2013, Preparation and Characterization of Rubbery Epoxy/Multiwall Carbon Nanotubes Composites Using Amino Acid Salt Assisted Dispersion Technique, Express Polymer Letters, 7(4).

[13] Moniruzzaman, M., Winey, K. I., 2006, Polymer Nanocomposites Containing Carbon Nanotubes, Macromolecules, 39(16), 5194-5205.

[14] Ma, P. C., Mo, S. Y., Tang, B. Z., Kim, J. K., 2010, Dispersion, Interfacial Interaction and ReAgglomeration of Functionalized Carbon Nanotubes In Epoxy Composites. Carbon, 48(6), 18241834.

[15] Kumar, M., Ando, Y., 2010, Chemical Vapor Deposition of Carbon Nanotubes: A Review on Growth Mechanism and Mass Production, Journal of Nanoscience and Nanotechnology, 10(6), 3739-3758.

[16] Esteves, L. M., Oliveira, H. A., Passos, F. B., 2018, Carbon Nanotubes As Catalyst Support In Chemical Vapor Deposition Reaction: A Review, Journal of Industrial and Engineering Chemistry, 65, 1-12.

[17] Ye, X. R., Lin, Y., Wang, C., Engelhard, M. H., Wang, Y., Wai, C. M., 2004, Supercritical Fluid Synthesis and Characterization of Catalytic Metal Nanoparticles on Carbon Nanotubes, Journal of Materials Chemistry, 14(5), 908-913.

[18] Öncel, Ç., Yürüm, Y., 2006, Carbon Nanotube Synthesis Via The Catalytic CVD Method: A Review on The Effect of Reaction Parameters, Fullerenes, Nanotubes, And Carbon Nonstructures, 14(1), 1737.

[19] Li, Y., Mann, D., Rolandi, M., Kim, W., Ural, A., Hung, S., Wang, Q., 2004, Preferential Growth of Semiconducting Single-Walled Carbon Nanotubes By A Plasma Enhanced CVD Method, Nano Letters, 4(2), 317-321.

[20] Igbokwe, E. C., Daramola, M. O., Iyuke, S. E., 2019, Production of Carbon Nanotube Yarns Via Floating Catalyst Chemical Vapor Deposition: Effect Of Synthesis Temperature On Electrical Conductivity, Results In Physics, 15, 102705.

[21] Janas, D., Koziol, K. K., 2016, Carbon Nanotube Fibers and Films: Synthesis, Applications and Perspectives of the Direct-Spinning Method, Nanoscale, 8(47), 19475-19490.

[22] Bagheri, H., Hashemipour, H., 2018, Comparison of Two Methods of Carbon Nanotube Synthesis: CVD and Supercritical Process (A Review), Int. J. Bio-Inorg. Hybr. Nanomater, 7(3), 199-204.

[23] Jourdain, V., Bichara, C., 2013, Current Understanding of the Growth of Carbon Nanotubes in Catalytic Chemical Vapour Deposition, Carbon, 58, 2-39.

[24] Seo, J. W., Magrez, A., Milas, M., Lee, K., Lukovac, V., Forró, L., 2007, Catalytically Grown Carbon Nanotubes: From Synthesis To Toxicity, Journal of Physics D: Applied Physics, 40(6), R109.

[25] Shamsudin, M. S., Mohammad, M., Zobir, S. A. M., Asli, N. A., Bakar, S. A., Abdullah, S., Mahmood, M. R., 2013, Synthesis and Nucleation-Growth Mechanism of Almost Catalyst-Free Carbon Nanotubes Grown From Fe-Filled Sphere-Like Graphene-Shell Surface, Journal of Nanostructure In Chemistry, 3(1), 13. 
[26] Suriani, A. B., Azira, A. A., Nik, S. F., Nor, R. M., Rusop, M., 2009, Synthesis of Vertically Aligned Carbon Nanotubes Using Natural Palm Oil As Carbon Precursor, Materials Letters, 63(30), 27042706.

[27] Yang, K., Gu, M., Guo, Y., Pan, X., Mu, G., 2009, Effects of Carbon Nanotube Functionalization On The Mechanical and Thermal Properties of Epoxy Composites, Carbon, 47(7), 1723-1737.

[28] Kim, Y. J., Shin, T. S., Do Choi, H., Kwon, J. H., Chung, Y. C., Yoon, H. G., 2005, Electrical Conductivity of Chemically Modified Multiwalled Carbon Nanotube/Epoxy Composites, Carbon, 43(1), 23-30. 